\title{
Towards Liver-Directed Gene Therapy: Retrovirus-Mediated Gene Transfer into Human Hepatocytes
}

\author{
Mariann Grossman, Steven E. Raper, and James M. Wilson \\ Departments of Intemal Medicine, Surgery, and Biological Chemistry, and The Howard Hughes Medical Institute, \\ The University of Michigan Medical School, Ann Arbor Michigan 48109 \\ Received 4 September 1991
}

\begin{abstract}
Liver-directed gene therapy is being considered in the treatment of inherited metabolic diseases. One approach we are considering is the transplantation of autologous hepatocytes that have been genetically modified with recombinant retrovinuses ex vivo. We describe, in this report, techniques for isolating human hepatocytes and efficiently transducing recombinant genes into primary cultures. Hepatocytes were isolated from tissue of four different donors, plated in priman culture, and exposed to recombinant retrovinuses expressing either the LacZ reporter gene or the cDNA for rabbit LDL receptor. The efficiency of gene transfer under optimal conditions, as determined by Southern blot analysis, varied from a maximum of one proviral copy per cell to a minimum of 0.1 proviral copy per cell. Cytochemical assays were used to detect expression of the recombinant derived proteins, E. coli $\beta$-galactosidase and rabbit $L D L$ receptor. Hepatocytes transduced with the LDL receptor gene expressed levels of receptor protein that exceeded the normal endogenous levels. The ability to isolate and genetically modify human hepatocytes, as described in this report, is an important step towards the development of liver-directed gene therapies in humans.
\end{abstract}

\section{INTRODUCTION}

Somatic gene therapy is being considered in the treatment of a variety of diseases (1). We are developing approaches for treating inherited metabolic disorders in which therapeutic genes are transferred into hepatocytes (2). One specific strategy, called ex vivo gene therapy, is based on transplantation of autologous, genetically modified, hepatocytes. Our proposed protocol for human applications of ex vivo gene therapy is summarized below. Liver tissue will be harvested from a patient and collagenase perfused ex vivo to release a suspension of hepatocytes. The viable hepatocytes will be plated in culture and exposed to stocks of recombinant retroviruses capable of efficiently transducing recombinant genes into the genome of the recipient hepatocytes. The genetically modified hepatocytes will then be harvested and transplanted into the patient from which they were derived.

The feasibility of ex vivo liver-directed gene therapy in humans is supported by extensive experiments in small animal models. We and others have used recombinant retroviruses to transduce a variety of genes into primary cultures of hepatocytes derived from mouse $(3)$, rat $(4,5)$, and rabbit $(6,7)$. Various techniques for transplanting hepatocytes have been described; however, most of these approaches have little relevance to therapeutic applications because of limita- 
tions in the capacity, durability, or function of the engrafted cells (for example see 8,9 ). More recent studies that transplant hepatocytes into the portal circulation or the peritoneal cavity on microcarrier beads appear more promising (10-13).

The specific disease we are considering for early human applications of liver-directed gene therapy is homozygous familial hypercholesterolemia (FH). This disorder is caused by a deficiency of LDL receptors and is associated with severe hypercholesterolemia and premature coronary heart disease (14). Orthotopic liver transplantation leads to marked improvement in the dyslipidemia of $\mathrm{FH}$, suggesting that liver-directed gene transfer may be sufficient for some level of therapeutic efficacy $(15,16)$. We have used an animal model of $\mathrm{FH}$, the Watanabe heritable hyperlipidemic (WHHL) rabbit, to develop ex vivo gene therapies directed to liver $(6,17)$. In a previous study, we isolated WHHL hepatocytes, established primary cultures, and used recombinant retroviruses to transduce functional LDL receptor genes into the hepatocytes. Transplantation of the genetically corrected hepatocytes into allogeneic WHHL recipients was associated with transient diminutions in serum cholesterol (17).

Essential to the development of liverdirected gene therapy in humans are methods for isolating viable human hepatocytes and efficiently transducing therapeutic genes into the hepatocytes. We describe in this report our experience with hepatocyte isolation from livers from four donors and the genetic modification of these cells with recombinant retroviruses that express different genes.

\section{MATERIALS AND METHODS}

Hepatocyte Isolation and Primary Cultures. Livers were perfused with UW solution or Euro-Collins solution and stored at $4^{\circ} \mathrm{C}$ prior to hepatocyte isolation. A portion of the liver
(60-124 g) was removed and $1 \times$ Leffert's solution (18), pH 7.4, containing $0.5 \mathrm{mM}$ EGTA was perfused into major vessels through a 16-gauge angiocath for $10 \mathrm{~min}$. This was followed by perfusion with $1 \times$ Leffert's solution, $\mathrm{pH} 7.4$, without EGTA for 5 min, and then $1 \times$ Leffert's, pH 7.4, containing $5 \mathrm{mM} \mathrm{CaCl}, 5 \mathrm{mg} / \mathrm{ml} \mathrm{BSA}$ (fraction $\mathrm{V}$ ), and $0.5 \mathrm{mg} / \mathrm{ml}$ collagenase $\mathrm{D}$ (Boehringer Mannheim) for 18-24 min. The collagenase perfusion was terminated when the liver softened and began to dissociate. All solutions were filter sterilized prior to use and oxygenated at $37^{\circ} \mathrm{C}$ during the perfusions. Flow rates varied from 100 to 125 $\mathrm{ml} / \mathrm{min}$. The perfused liver was teased apart with a rubber policeman and forceps and filtered through a presterilized $85-\mu \mathrm{m}$ nylon mesh at $4^{\circ} \mathrm{C}$ into a sterile flask containing RPMI 1640 medium with $10 \%$ fetal bovine serum and $1 \%$ penicillin/streptomycin (medium A). The filtered hepatocytes were pelleted by centrifugation three times at $50 \mathrm{~g}$ for $1 \mathrm{~min}$, resuspended in medium $\mathrm{A}$, and viable cells were quantified by exclusion of trypan blue.

Hepatocytes were plated at 2 or $4 \times 10^{6}$ cells $/ 10-\mathrm{cm}$ plate overnight in hormonally defined medium (HDM) containing 10\% fetal calf serum onto Primaria plates (19). Each subsequent day the media was replaced with fresh HDM without serum.

Retroviral-Mediated Gene Transfer. Amphotropic viral producer cell lines made from the BAG (20) and AFP-BA-rLDLR (Grossman et al., in preparation) vectors were used in these experiments. Fresh virus was harvested from confluent plates of viral producers in DMEM containing $10 \%$ calf serum and $1 \%$ penicillin/streptomycin, supplemented with $8 \mu \mathrm{g} / \mathrm{ml}$ of polybrene, and placed directly onto the hepatocyte cultures for a 16 -h period beginning $48 \mathrm{~h}$ (day 2) or $72 \mathrm{~h}$ (day 3 ) after initial plating.

DNA and RNA Analyses. Cultures were analyzed $48 \mathrm{~h}$ after infection for the presence 
of proviral DNA and viral-derived RNA. Total cellular DNA was harvested, restricted with endonucleases, and analyzed by the method of Southern using probes derived from either a 1067-bp Pstl fragment from rabbit LDL receptor CDNA (for LDL receptor-transduced cultures) or a 877-bp ClaI to Bglll fragment from the lac $Z$ gene (for BAG-transduced cultures) (6). Total cellular RNA was harvested and analyzed by blot analysis as described (6). Filters containing RNA from LDL receptor-transduced cells were probed with the fragment described for the Southern blot studies.

Cytochemical Assays for Recombinant Gene Expression. Hepatocytes were assayed for recombinant gene expression $48 \mathrm{~h}$ after infection. BAG-transduced hepatocytes were subjected to the chromogenic histochemical assay for $\beta$-galactosidase (20). LDL receptortransduced cells were incubated with fluorescent-labeled DiI-LDL $(10 \mu \mathrm{g} / \mathrm{ml})$ for $6 \mathrm{~h}$, washed in PBS, and visualized under phasecontrast and fluorescence microscopy (6).

\section{RESULTS AND DISCUSSION}

A portion of liver tissue from four different donors, labeled $\mathrm{Z1}$ through $\mathrm{Z} 4$, was used for hepatocyte isolation. Salient features of the patients and the hepatocyte isolations are summarized in Table 1. Liver sections from three of the donors were available because the organ had been surgically reduced prior to transplantation; the fourth organ had been harvested but not used for transplantation because the donor was hemodynamically unstable and had elevated liver function tests. The organs were perfused with UW solution $(\mathrm{Z} 1, \mathrm{Z} 2, \mathrm{Z} 3)$ or Euro-Collins solution (Z4) and stored for variable periods of time prior to hepatocyte isolation ( $30 \mathrm{~min}$ to $36 \mathrm{~h}$ ). The age of the donors ranged from 22 months to 44 years.

Hepatocytes were isolated by collagenase perfusion of the major vessels using a modification of the technique shown to be successful in isolating hepatocytes from rabbits (17). The viability of recovered hepatocytes ranged from $85 \%$ to $98 \%$, while the recovery of viable cells ranged from 3 to $33 \times 10^{6}$ cells $/ g$ wet weight of tissue. The hepatocytes were plated overnight in HDM containing bovine fetal serum onto Primaria tissue culture plates and were subsequently maintained in serum free HDM. Figure 1 presents serial phase-contrast micrographs of cultures from patient Z2. Plating efficiencies ranged from approximately $50 \%$ to greater than $95 \%$. The cultures were seeded at various subconfluent densities and rapidly grew to confluence within $72 \mathrm{~h}$ of the initial

\begin{tabular}{lllll}
\hline \multicolumn{4}{c}{ Table 1. Summary of Organ Donors and Hepatocyte Isolations } \\
\hline \multicolumn{1}{c}{$\mathrm{Z} 1$} & \multicolumn{2}{c}{$\mathrm{Z} 2$} & $\mathrm{Z} 3$ & $\mathrm{Z} 4$ \\
\hline Donor & & & & \\
Age & 22 months & 4 years & 44 years & 18 years \\
Sex & male & female & male & male \\
Clinical & stable & stable & stable & shock, increased LFTs \\
Organ & reduction & reduction & reduction & unsuitable for Tx. \\
Perfusate & $\mathrm{UW}$ & $\mathrm{UW}$ & $\mathrm{UW}$ & Euro-Collins \\
Time & $16 \mathrm{~h}$ & $2 \mathrm{~h}$ & $36 \mathrm{~h}$ & 30 min \\
Isolation and culture & & & & \\
Weight $(g)$ & $\sim 60$ & 71 & $\sim 60$ & 124 \\
Viability $(\%)$ & 89 & 98 & 85 & 92 \\
Recovery $\left(\times 10^{4}\right)$ & 2 & 1.5 & 0.2 & 0.5 \\
Plating efficiency $(\%)$ & $>95$ & 50 & $>95$ & $>95$ \\
\hline
\end{tabular}

"Time between organ harvest and hepatocyte isolation.

${ }^{b}$ The donor was hemodynamically unstable and had elevated liver function tests prior to organ harvest. 

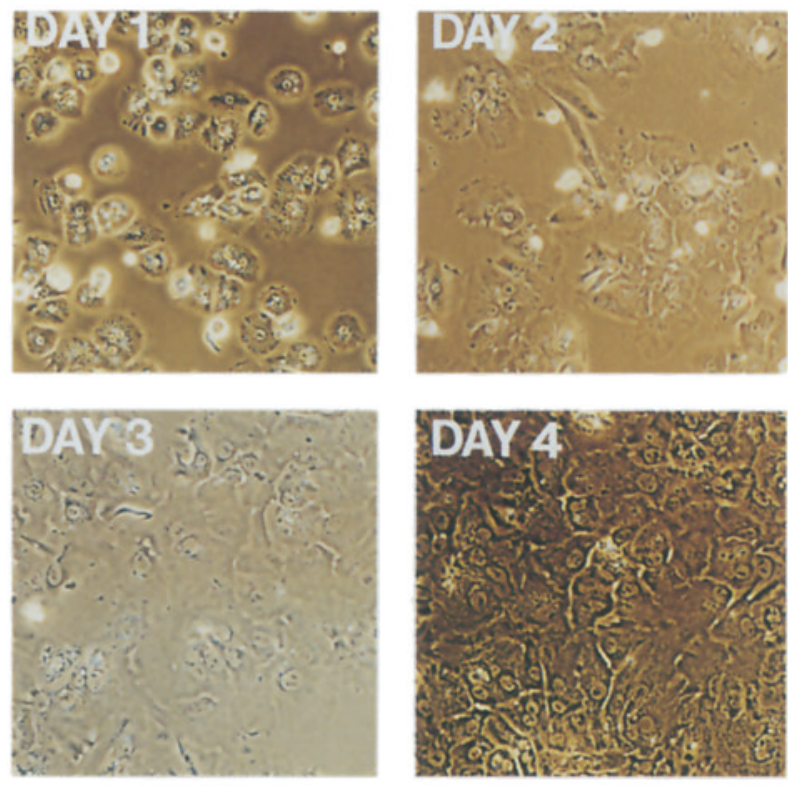

Fig. 1. Micrographs of cultured hepatocytes. Hepatocytes from patient $Z 2$ were plated at 4 $\times 10^{6} / 10-\mathrm{cm}$ plate and maintained in culture as described in Materials and Methods. Microm graphs of the culture were taken one, two, three, and four days after the initial seeding Magnification is $100 \times$. plating. Hepatocytes were maintained in primary culture for a total of four to five days.

Experiments were performed to maximize the efficiency of retroviral-mediated gene transfer. Two recombinant retroviruses were used to infect the primary cultures from each patient; both types of virus were produced in the amphotropic packaging cell line $\Psi$ crip (20). One recombinant virus was produced from the previously described $B A G$ vector that expresses the lac $Z$ gene from a transcript initiated at the $5^{\prime}$ LTR and a gene encoding Neo from SV40 sequences located internal to the viral transcriptional unit (20). Another recombinant virus was produced from a vector called AFP-BArLDLR, which expresses rabbit LDL receptor from a transcript initiated at promoter sequences that are derived from the chicken $\beta$-actin gene along with enhancer sequences from the mouse $\alpha$-fetoprotein gene (Grossman et al., in preparation). The relative titer of each virus was estimated by infecting subconfluent plates of NIH3T3 cells and harvesting total cellular DNA for Southern blot analysis. BAG-infected cells contain approximately 0.5 copy of proviral DNA per cell, while LDL receptor-infected cells contain approximately one copy of proviral DNA per cell.

Based on our previous experiences with primary cultures of rat $(5)$ and rabbit $(6,17)$ hepatocytes, we developed a protocol for efficiently infecting human primary hepatocytes. The protocol was designed to maximize gene transfer and minimize the time the hepatocytes are maintained in culture. Hepatocytes were seeded at different densities ( 2 or $4 \times 10^{6} / 10-\mathrm{cm}$ plate) and exposed to the viruses for a single 12 -h period beginning 48 h (day 2) or 72 h (day 3) after initial plating. Cells were harvested $48 \mathrm{~h}$ after completion of the infection and total cellular DNA was prepared for blot analysis to estimate the abundance and integrity of integrated proviral DNA in the unselected population. Representative experiments are presented in Fig. 2. Efficiency of gene transfer with the LDL receptor virus ranged from a maximum of one proviral copy per diploid genome for $Z 1$ to a minimum of 0.1 proviral copy per diploid genome for $\mathrm{Z} 2$. Infection efficiency was consistently highest when the cells were exposed to virus $48 \mathrm{~h}$ after plating; density of 


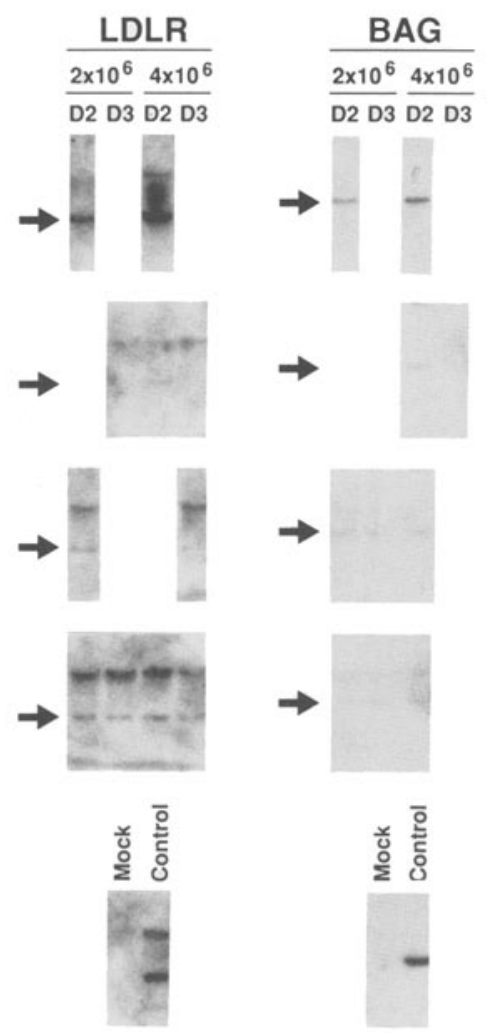

Fig. 2. Southern blot analysis of DNA from infected hepatocytes. Total cellular DNA $(10 \mu \mathrm{g})$ was restricted with NheI and analyzed by the method of Southern. The figure is organized in the following manner: The left columns contain DNA from LDL receptor-infected cells; the right columns contain DNA from BAGinfected cells. Hepatocytes were plated at 2 or $4 \times 10^{6}$ and infected on day 2 or day 3 . DNAs were analyzed for each patient $(Z 1-Z A)$. The bottom portion of the figure contains DNA $(10 \mu \mathrm{g})$ from mock-infected hepatocytes alone ("Mock") or supplemented with plasmid DNA $(7.5 \mathrm{pg})$ that represents approximately one proviral copy per cell ("control"). The proviral derived band is indicated by an arrow. The larger band at $10 \mathrm{~kb}$ represents hybridization to endogenous sequences.

plating did not consistently affect the efficiency of gene transfer. The absolute level of gene transfer was less with the lower-titer $\mathrm{BAG}$ virus, although the effects of plating density and time of exposure to virus on gene transfer were similar.

Expression of the integrated LDL receptor provirus in human hepatocytes was studied by RNA blot analysis, which mea- sures the steady-state level of recombinant RNAs (Fig. 3). The AFP-BA-rLDLR vector contains two transcriptional units: transcription from the 5' LTR produces a 5.6-kb RNA responsible for passage of the virus, while a transcript initiated at the $\beta$-actin promoter produces a $3.4-\mathrm{kb}$ transcript responsible for translation of the LDL receptor protein. The 3 LTR in the plasmid vector, which has been deleted of enhancer sequences, forms the template for both LTRs in the integrated provirus (21). The rationale for this modification is to minimize the LTR transcript and maximize the translated $\beta$-actin transcript in

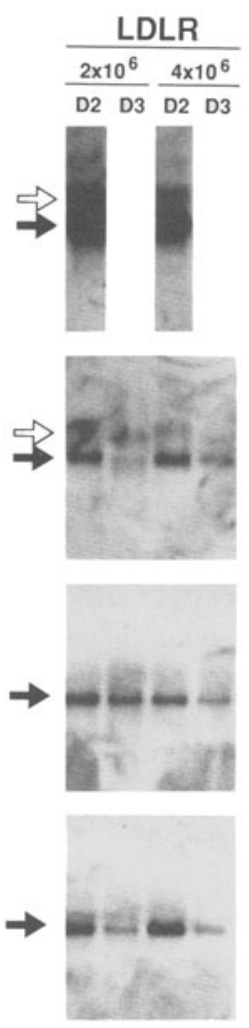

Fig. 3. Northern blot analysis of RNA from infected bepatocytes. Total cellular RNA $(10 \mu \mathrm{g})$ was analyzed for recombinant transcripts as described in Materials and Methods. RNAs from LDL receptor-transduced cultures were studied. The figure is organized as described for the Southern blots in Fig. 3. The open arrow indicates the location of the LTR-directed $5.6-\mathrm{kb}$ transcript, the filled arrow indicates the location of the $\beta$-actin-directed 3.4-kb transcript. 
the infected cells. Both the $5.6-\mathrm{kb}$ and $3.4-\mathrm{kb}$ recombinant-derived LDL receptor transcripts were detected in infected hepatocyte cultures from each donor. As expected, the smaller transcript initiated from the internal promoter was more abundant than the larger LTR-initiated transcript.

Hepatocyte cultures transduced with either the BAG or the LDL receptor virus were analyzed for recombinant gene expression using cytochemical analyses (Fig. 4). Expression of $E$. coli $\beta$-galactosidase in the BAG-transduced cells was detected with a histochemical stain using the chromogenic substrate X-gal that produces a diffuse blue cytoplasmic precipitate $(20)$. A representative X-gal stain of the $\mathrm{Z} 1$ infected hepato-

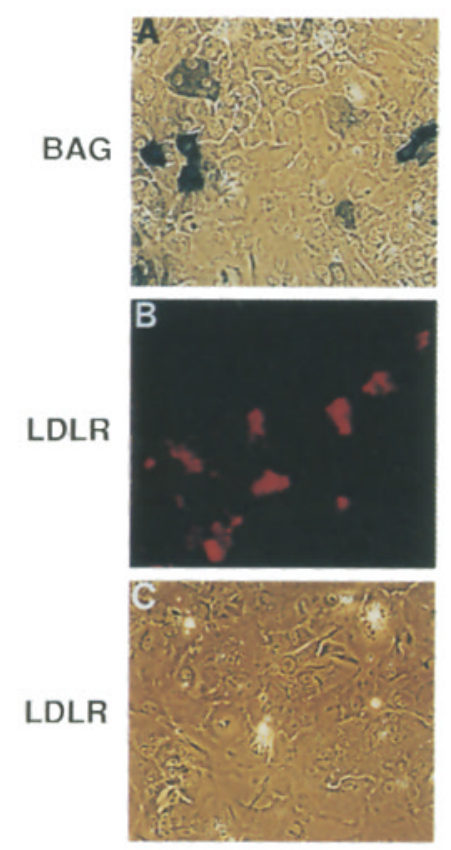

Fig. 4. Cytochemical analysis of recombinant gene expression in transduced hepatocytes. (A) Hepatocytes from $Z 1$ plated at $4 \times 10^{6} \mathrm{cells} / 10-\mathrm{cm}$ plate and infected on day 2 with $B A G$ virus were subjected to the chromogenic assay for $\beta$-galactosidase activity. (B and C) Hepatocytes from $\mathrm{Z} 2$ plated at $2 \times 10^{6}$ cells $/ 10-\mathrm{cm}$ plate and infected on day 3 with $L D L$ receptor virus were incubated with fluorescent labeled LDL and a representative field was visualized under fluorescent $(B)$ and phase-contrast microscopy (C). Magnification is $100 x$. cytes is shown in Fig. 4A. This analysis demonstrated lac $Z$ expression in approximately $10-25 \%$ of cells, thereby confirming the estimate of gene transfer provided by Southern blot analysis ( 0.3 proviral copies per cell, see Fig. 2). Expression of recombinant LDL receptor protein was analyzed using an in situ functional assay that detects uptake of fluorescent-labeled LDL (6). Mock infected hepatocytes demonstrated low levels of fluorescence representing uptake via the endogenous receptors (data not shown). Analysis of LDL receptor-transduced hepatocytes from patient $Z 2$ revealed a subpopulation of highly fluorescent cells comprising approximately $20 \%$ of the culture (Fig. 4B and $\mathrm{C}$ ). This result indicates that the recombinant-derived receptor is functional and can be expressed at levels in excess of the normal endogenous receptor.

This study has important implications in the development of liver-directed gene therapies in humans. We describe a technique for reproducibly isolating high yields of viable hepatocytes. The isolated hepatocytes were plated onto tissue culture plastic with high efficiency and allowed to expand over a short period of time in primary culture to form confluent monolayers. The quality of the cultures and ability to transduce genes were shown to be independent of the age (22 months to 44 years of age) and sex (three males and one female) of the donor and the duration of time that the organ was preserved prior to hepatocyte isolation ( $30 \mathrm{~min}$ to $36 \mathrm{~h}$ ).

The efficacy of ex vivo gene therapy in the liver for the treatment of metabolic diseases is directly linked to the efficiency of genetic reconstitution. The net level of genetic reconstitution is related to the efficiency of gene transfer, the level of recombinant gene expression, and the capacity of hepatocyte engraftment. We have described methods that utilize recombinant retroviruses to efficiently and stably transduce recombinant genes into primary cul- 
tures of hepatocytes. Gene transduction can be achieved soon after the initial seeding (i.e., $72 \mathrm{~h}$ ) thereby minimizing the time the hepatocytes are in culture prior to transplantation. In the case of LDL receptor, expression of the recombinant protein actually exceeds that of the endogenous protein.

It is hoped that the techniques of hepatocyte isolation and gene transfer described in this report, combined with methods for transplanting hepatocytes, will provide the basis for ex vivo gene therapies for inherited metabolic diseases.

\section{ACKNOWLEDGMENTS}

We sincerely appreciate the cooperation of the Liver Transplant Team of the University of Michigan for help in obtaining liver tissue and Stanford Research Institute International (Menlo Park, California) for advice regarding hepatocyte isolation. Joe Cornicelli kindly provided the DiI-LDL. Supported by the Howard Hughes Medical Institute and the University of Michigan Hospitals.

\section{LITERATURE CITED}

1. Friedman, T. (1989). Science 244:1275-1281.

2. Wilson, J.M., and Chowdhury, J.R. (1990). Mol. Biol. Med. 7:22-232.

3. Peng, H., Armentano, D., MacKenzie-Graham, L., Shen, R.F., Darlington, G., Ledley, F.D., and Woo, S.L. (1988) Proc. Natl. Acad. Sci. U.S.A. 85:81468150 .

4. Wolff, J.A., Yee, J.K., Skelly, H.F., Moores, J.C. Respess, J.G., Friedmann, T., and Leffert, H. (1987). Proc. Natl. Acad. Sci. U.S.A. 84:3344-3348.

5. Wilson, J.M., Jefferson, D.M., Chowdhury, J.R., Novikoff, P.M., Johnston, D.E., and Mulligan, R.C. (1988). Proc. Natl. Acad. Sci. U.S.A. 85:3014-3018.

6. Wilson, J.M., Johnston, D.E., Jefferson, D.M, and
Mulligan, R.C. (1988). Proc. Natl. Acad.Sci. U.S.A. 85:4421-4425.

7. Armentano, D., Thompson, A.R., Darlington, G., and Woo, S.L. (1990). Proc. Natl. Acad. Sci. U.S.A. 87:6141-6145.

8. Jirtle, R.L., Bites, C., and Michalopoulos, G. (1980). Am. J. Pathol. 101:115-122.

9. Makowka, L., Rotstein, L.E., Falk, R.E., Falk, J.A., Zuk, R., Langer, B, Blendis, L.M., and Phillips, M.J. (1981). Transplant. Proc. 13;855-859.

10. Demetriou, A.A., Whiting, J.F., Feldman, D., Levenson, S.M., Chowdhury, N.R., Moscioni, A.D., Kram, M., and Chowdhury, J.R. (1986). Science 233:1190-1192.

11. Patel, A., Hardy, M., Chowdhury, N.R., Wajsman, R., Sandoval, M., Wilson, JM., and Chowdhury, J.R. (1989). Mol. Biol. Med. 6:187-196.

12. Gupta, S., Chowdhury, N.R., Jagtiani, R., Gustin, K., Aragona, E., Shafritz, D.A., Chowdhury, J.R., and Burk, R.D. (1990). Transplantation 50:472475.

13. Ponder, K.P., Gupta, S., Leland, F., Darlington, G., Finegold, M., DeMayo, I., Ledley, F.D., Chowdhury, J.R., and Woo, S.L. (1991). Proc. Natl. Acad. Sci. U.S.A. 88:1217-1221.

14. Goldstein, J.L., and Brown, M.S. (1989). In Metabolic Basts of Inherited Disease II, (eds.) Scriver, C.R., Beaudet, A.L., Sly, W.S., and Valle, D. (McGraw-Hill, New York), pp. 1215-1250.

15. Starzl, T.E., Bahnson, H.T., Hardesty, R.L., Iwatsuki, S., Gartner, J.C., Bilheimer, D.W, Shaw, B.W., Griffith, B.P., Zitelli, B.J., and Malatack, J.J. (1984) Lancet 0:1382-1383.

16. Hoeg, J.M., Starzl, T.E., and Brewer, H.B. (1987). Am. J. Cardiol. 59:705-707.

17. Wilson, J.M., Chowdhury, N.R., Grossman, M., Wajsman, R., Epstein, A., Mulligan, R.C., and Chowdhury, J.R. (1990). Proc. Natl. Acad. Sci. U.S.A. 87:8437-8441.

18. Leffert, H.L., Koch, K.S. Moran, T, and Williams, M. (1979). Methods Enzymol. 58:536-544.

19. Enat, R., Jefferson, D.M., Ruiz-Opazo, N., Gat* maitan, Z., Leinwand, L.A., and Reid, L.M. (1984). Proc. Natl. Acad. Sci. U.S.A. 81:1411-1415.

20. Price, J., Turner, D., and Cepko, C. (1987). Proc Natl. Acad. Sci. U.S.A. 84:156-160.

21. Danos, O., and Mulligan, R.C. (1988). Proc. Natl. Acad. Sci. U.S.A. 85:6460-6464.

22. Sheau-Fung, Y.U., Von Ruden, T, Kantoff, P.W., Garber, C., Seiberg, M., Ruther, U., Anderson, W.F., Wagner, E.F., and Giboa, E. (1986). Proc. Natl. Acad. Sci. U.S.A. 83:3194-3198. 